\title{
The Use of Virtual Reality on Illustration-Based Virtual Environments: An Experimenter Preliminary Study
}

\author{
Perng Jeu Ng \\ Muiltimedia and Digital Animation \\ Universiti Sains Malaysia \\ Penang, Malaysia \\ perngjeu@gmail.com
}

\author{
Mariam Mohamad \\ Postgraduate Studies, Network and Alumni \\ Universiti Sains Malaysia \\ Penang, Malaysia \\ mmohamad@usm.my
}

\author{
Kien Tsong Chau \\ Interactive Multimedianame \\ Universiti Sains Malaysia \\ Penang, Malaysia \\ chaukientsong@usm.my
}

\begin{abstract}
Technology education has not only become a network of gathering and sharing ideas, but also a platform for students and teachers to research, collaborate, and differentiate (Elliot, 2016). Virtual Reality is one of the high demand and attractive technology to student community, especially the advancement in immersive technology and visual environment. The use of visual become crucial and important when user interact with the learning content, and the visual types in virtual reality are 3D Model, 2D Photosphere, and Mixed Environment. With the increasing demand for innovation in education for secondary school standard, and the advancement of visualization technology, the application of virtual reality in a range of historical teaching and learning materials can be utilized in virtual reality environments. This paper demonstrates the attempt to visually enhance Virtual Environments in form of 360 VR Illustration through the use of image based techniques.
\end{abstract}

Keywords: virtual reality, visual design, image processing, immersion, virtual environments

\section{INTRODUCTION}

In recent years, Virtual Reality (VR) and virtual learning environment have become increasingly explored. VR, through simulations, could help overcome the limitations of language learning within the four walls of the classroom. The potential of VR in education however is exploited only quite recently by educators and institutions. VR serve as an experience in which a person is surrounded by a threedimensional computer-generated representation, and is able to move around in the virtual world and see it from different angles, to reach into it, grab it and reshape it. The paper will thus first discuss the underlying theories and recent research work on virtual environment in education. The conceptual framework for implementation of VR to cultural heritage sites such as building will also be presented. The paper will also present the basic architecture and the technical aspects of the offshore platform virtual environment. Basically, the interactive and illustration immersive features of a built virtual environment would provide the learners a rich, interactive and contextual setting to support experiential and active learning.

\section{LITERATURE REVIEW}

\section{A. Virtual Reality and Multimedia}

Interactive multimedia programs take the idea of learning and doing in which the learning process becomes active and enhance the interactivity level in between learners and the programs. Interactive multimedia learning is a process, rather than a technology, that places new learning potential into the hands of users. [1] stated that the variety of learning experiences that can be offered by the use of a mix of learning environments, such as simulations and the use of interactive multimedia. [2] mentioned that the key features of multiple media, interactivity and the method of delivery of information, can enhance the learners' experiences and build to deeper understanding on learning through supporting and contextualization of the interactive multimedia being presented. It is important to investigate the components that form the learning experience and work towards the identification of issues that might be causing a mismatch between the interactions used to facilitate learning and the individual characteristics and the needs of the user.

Since these traditional approaches "do not encourage students to question what they have learnt or to associate with previously acquired knowledge" [3], and [4] stated, problem-based learning is seen as an innovative measure to encourage students to "learn how to learn" via "reallife" problems. The purpose of multimedia instructional design is to ensure "to know more about the best types of feedback to give" and about the techniques that can "ensure learners reflect on feedback" [5]. In this research, multimediamediated problem-based learning (PBL) environment is proposed. The method of this learning mode is constructivist in approach whereby the students participate actively in their own learning process and construct their own knowledge [6]. The focus and main concern of interactive multimedia learning is to moving from good to better user experience.

\section{B. Current Virtual Reality System}

Virtual Reality (VR) and Virtual Environment (VE) are used in computer community interchangeably and developed in rapid system. The use of Virtual Reality (VR) can enhance the real-life experience. Aldrich (2004) stated that a stimulation can provide authentic and relevant scenarios, make use of pressure situation that tap users' emotions and force them to act, they provide a sense of unrestricted options and they can replayed. One of the major factors of using virtual reality to deliver knowledge and information is that it is highly motivating. The attitude of participants toward virtual reality as a tool in educational process, and towards virtual learning 
environment on specific disciplines, found participants had a favorable attitude towards virtual reality in educational process. VR functional on holds the attention of students. This has been documented in the reports of a number of research studies. Students find it exciting and challenging to walk through an environment in three dimensions and interact with environment. VR allows examination of an object from a distance, showing the whole rather than a part. The learner decides what to do when interacting with the virtual environment. VR allows a learner to proceed through. VR provides experience with new technologies through actual use. A simulation of a new process with a new piece of equipment can train a worker. VR provides a way for some objectives to be taught via distance education which were previously impossible to teach in that way.

\section{Virtual Reality for the Cultural Heritage Preservation}

The integration of the research in the area of computer graphics, computer vision and 3D survey systems found as a common action field the virtual reconstructions of Cultural Heritage. This study included dealing with acquiring techniques, modelling, optimization, and final presentation of digital reconstructions using Virtual Reality paradigms that are still relevant today. The potentiality of VR applications to promote knowledge Cultural Heritage is proven by the development of a significant number of projects in this research area. The installation was a performance combining holography, projections 3D video mapping, andsound.

In conclusion, this study is to produce a VR application in term of delivering and recreating cultural heritage sites in the virtual world that looks interesting and real to learners to increase the level of learning. Another interest of this study is to understand how Virtual Reality cultural heritage site can promoting cultural heritage preservation in Malaysia. Through the VR experience, learners will be able to enjoy the sights and sounds of cultural heritage site, and increase their desire to understand the historic environment.

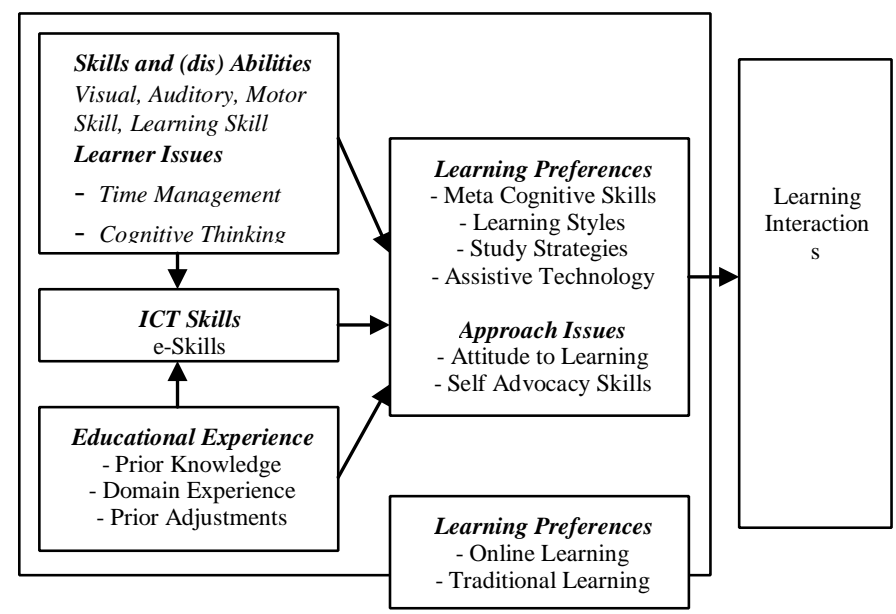

Figure. 1. A model of the challenge to blended learning form the learners' perspective

All these skills affect or are affected by the student's resilience and coping strategies within a given environment and by the learner's preference for the use of individual skills. There may also be elements of anxiety, fatigue and pain, which impact on all aspects of learning, in addition to time management and organizational abilities. The concept of learner characteristics provides a holistic overview of the learner and goes further than educationally based descriptions of a student that take a particular focus or slant.

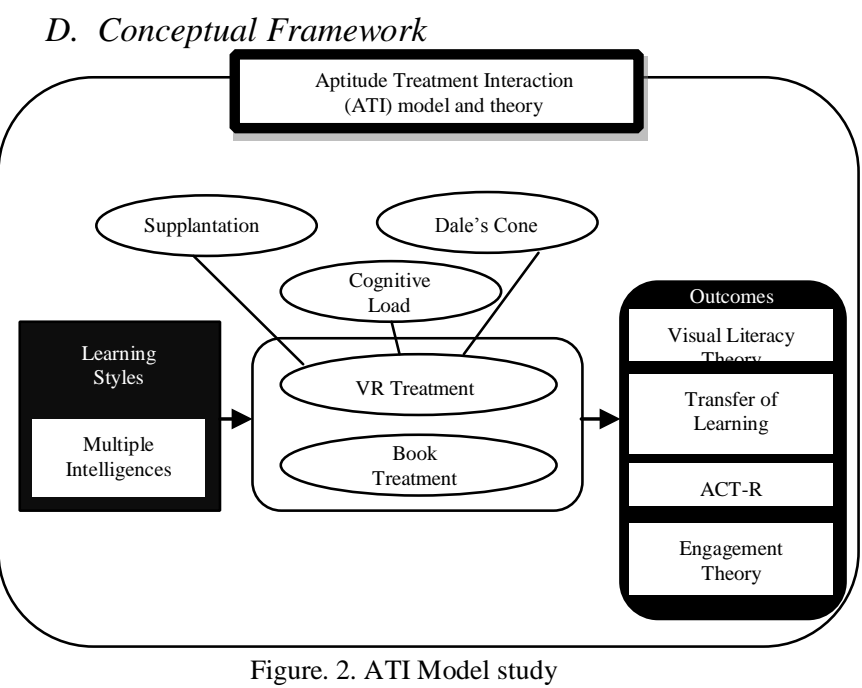

As shown in Figure 2, the entire study is an ATI Model study. The participants enter the study with their own intelligence type. After a brief survey to assess which intelligence type is strongest for the participant, each participant will go through one of two treatments: Virtual Reality (VR) or Textbook-style information. Supplantation, Cognitive Load, and Dale's Cone of Experience all affect the effectiveness of the VR treatment. Following the treatment, the participants will be tested on the instructional tools presented. The results of the study should be explained by the following theories: Visual Literacy Theory, Transfer of Training/Learning, ACT-R, and Engagement Theory.

\section{RESEARCH METHODOLOGY}

This research project requires gathering relevant data through the qualitative data collection tools, rooted in a qualitative research format that recognizes the importing of locating the research within a particular history, social, and cultural. Data collection will consists of observations and questionaires, a structured observation protocol will be developed as a guide for the semi-structured interviews. The aim of this project is to interview approximately 56 participants who embody a rage of identity background and communities. For observation part, participants will be monitored and observed while they are involved in interactive multimedia learning, participants are respond to a walkthrough of interactivity with multimedia platform over the course of this project that allow observer to provide more detailed and longitudinal view - the user experiences, reactions, user control and overall opinions on graphic, interactivity, and etc of multimedia.

A qualitative evaluation shall be utilized for this research project leveraging subjective methods such as 
questionnaire to collect substantive and relevant data. Upon collecting the qualitative data derived from said questionnaire, careful analysis shall be done (both manually and utilizing interactive multimedia) to prepare a SWOT (strengths, weaknesses, opportunities, and threats) to analyze how to best customize the course to the target participants. Recent research on intercultural communication and instructional design shall be consulted to validate collected data.

More specifically, the following research questions can be addressed to support the research objectives:

i) What suitable approach designs are required to advance the interactivity process with users' expectations?

ii) How different were users' experiences with the Multimedia Platform when their prior knowledge was considered?

Table 1. Research Questions and Data Collection Instruments.

\begin{tabular}{|l|l|}
\hline \multicolumn{1}{|c|}{$\begin{array}{c}\text { Research Questions and } \\
\text { Hypotheses }\end{array}$} & \multicolumn{1}{c|}{$\begin{array}{c}\text { Data } \\
\text { Collection } \\
\text { Instruments }\end{array}$} \\
\hline $\begin{array}{l}\text { i) What suitable approach designs are } \\
\text { required to advance the interactivity } \\
\text { process with users' expectations? }\end{array}$ & 1. Questionnaire \\
\hline $\begin{array}{l}\text { ii) How different were } \\
\text { users' experiences with the Multimedia } \\
\text { Platform when their prior } \\
\text { knowledge was considered? }\end{array}$ & $\begin{array}{l}\text { 1. Questionnaire } \\
\text { and Observation }\end{array}$ \\
\hline
\end{tabular}

\section{RESULTS OF ANALYSIS}

The virtual reality multimedia platform provided informative and attractive views of virtual environment. And this study is to study some of the students who were amazed by these images. These virtual environments were produced by two different artistic style in which categorized into 3Dbased and illustration-based production.

Table. 3. Participants' gender distribution

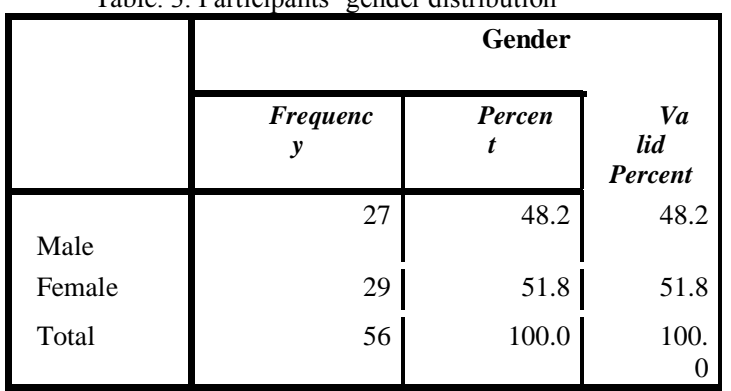

Table. 4. Secondary school students' preferences for different types of Multimedia

\begin{tabular}{|c|c|r|r|}
\hline & \multicolumn{3}{|c|}{ Elements of Multimedia } \\
& Frequency & Percent & $\begin{array}{c}\text { Valid } \\
\text { Percent }\end{array}$ \\
& 2 & 3.6 & 3.6 \\
Animation & 3 & 5.4 & 5.4 \\
Voiceover & 5 & 8.9 & 8.9 \\
Interactive & & & \\
Tools Als & 56 & 82.1 & 82.1 \\
Total & 56 & 100.0 & 100.0 \\
\hline
\end{tabular}

Figure 2 illustrates the students' learning modal preferences with regard to virtual environment.This learning environment is a visually rich multimedia system which was used as an instrument in the study. Figure 4 shows the visual features and interaction with virtual environment appear to be most popular amongst the 56 surveyed secondary school students.

Table. 5 .

Secondary school students' preferences for different types of information presentation

\begin{tabular}{|c|c|c|c|}
\hline & \multicolumn{3}{|c|}{ Students' Preference } \\
\cline { 2 - 4 } & $\begin{array}{c}\text { Frequen } \\
\text { cy }\end{array}$ & $\begin{array}{c}\text { Percen } \\
\boldsymbol{t}\end{array}$ & $\begin{array}{c}\text { Valid } \\
\text { Percent }\end{array}$ \\
& 10 & 17.9 & 17.9 \\
Verbal & 6 & 10.7 & 10.7 \\
Visual & 40 & 100.0 & 71.4 \\
Verbal \& & & & 100.0 \\
Visual & 56 & & \\
Total & & & \\
\hline
\end{tabular}

As illustrated in Figure 5, vast majority (71.4\%) of students indicated that the combination of verbal and visual as learning material played a very important role in understanding the concept.

Table. 6. Visual features in help of understanding learning materials

\begin{tabular}{|r|r|r|r|c|}
\hline & \multicolumn{4}{|c|}{ Important of Visual and Interactive } \\
\hline & Freque & Percent & $\begin{array}{c}\text { Valid } \\
\text { Percent }\end{array}$ & $\begin{array}{c}\text { Cumulative } \\
\text { Percent }\end{array}$ \\
& ncy & 91.1 & 91.1 & 91.1 \\
Yes & 51 & 8.9 & 8.9 & 8.9 \\
No & 5 & 100.0 & 100.0 & 100.0 \\
\hline tal & 56 & & & \\
\hline
\end{tabular}

Table. 7. Frequency distribution of factors as provided by students

\begin{tabular}{|r|r|r|r|r|}
\hline & \multicolumn{4}{|c|}{ Frequency Distribution of Factors } \\
\hline & Frequ & $\begin{array}{c}\text { Percen } \\
\text { ency }\end{array}$ & $\begin{array}{r}\text { Valid } \\
\text { Percent }\end{array}$ & $\begin{array}{c}\text { Cumulativ } \\
\text { e Percent }\end{array}$ \\
\hline Enjoyment & 5 & 8.9 & 8.9 & 8.9 \\
Speediness & 1 & 1.8 & 1.8 & 10.7 \\
Easiness & 1 & 1.8 & 1.8 & 12.5 \\
Real & 1 & 1.8 & 1.8 & 14.3 \\
World View & & 7.1 & 7.1 & 21.4 \\
Concept & 4 & 78.6 & 78.6 & 100.0 \\
Inclusion & 44 & & & \\
in Learning \\
Materials
\end{tabular}

The values of the two factors, Enjoyment (8.9\%) and Inclusion into Learning Materials (78.6\%) are highest among the others This shows that the VR Multimedia Method is more important for those two factors. Hence, it can be claimed that the overall importance of this method is very high in terms of students' learning preferences. 
Table. 8. Frequency distribution of factors as provided by students

\begin{tabular}{|c|c|c|c|c|}
\hline & \multicolumn{3}{|c|}{$\begin{array}{l}\text { 3D and } \\
\text { Illustration }\end{array}$} & \multirow[b]{2}{*}{$\begin{array}{l}\text { Cumul } \\
\text { ative } \\
\text { Percent }\end{array}$} \\
\hline & $\begin{array}{l}\text { Frequ } \\
\text { ency }\end{array}$ & $\begin{array}{l}\mathrm{Pe} \\
\text { rcent }\end{array}$ & $\begin{array}{l}\text { Valid } \\
\text { Percent }\end{array}$ & \\
\hline 3D Art View & 14 & $\begin{array}{r}25 . \\
0\end{array}$ & 25.0 & 25.0 \\
\hline \multirow[t]{2}{*}{$\begin{array}{l}\text { Illustration } \\
\text { Based Total }\end{array}$} & 42 & $\begin{array}{r}75 . \\
0\end{array}$ & 75.0 & 100.0 \\
\hline & 56 & $\begin{array}{r}10 \\
0.0\end{array}$ & 100.0 & \\
\hline
\end{tabular}

Students prefer illustration-based virtual environment compared to 3D art view due to illustration presented in way of more convince and attractive visual.

\section{CONCLUSION}

From this study, reported that visually illustrationbased virtual environment can provide a very effective teaching and learning environment. A virtual reality multimedia can even further enhance learning by incorporating more visual features. This situations lead to where the learners could immerse themselves in the environment and interact with objects and scenarios in a dynamic manner.

Future investigation will include exploring ways of designing educational virtual reality multimedia for other topic and virtual environment.

\section{ACKNOWLEDGMENT}

Thanks to my beloved supervisors, Dr Mariam and Dr Chau on continuous support and guidance. Last but not least, appreciate to REKA 2018 conference committees' effort.

\section{REFERENCES}

[1] R. Young, The key to e-learning is b-learning, HCi Journal of Information Development. Retrieved from http:// www.hci.com.au/hcisite2/journal/Key\%20to\%20learning\% 20is\%20bl earning.htm, accessed 18 January 2018.

[2] Cairncross, S \& Mannion, M. .Interactive Multimedia and Learning: Realizing the Benefits. Innovations in Education \& Teaching International, 38 (2), 156-164. 2001

[3] Boud, D. \& Feletti, G. . The Challenge of Problem-Based Learning, (2nd Ed.), London: Kogan Page. 1999.

[4] Teo, R. \& Wong, A. . Does Problem Based Learning Create A Better Student: A Refelection? Paper presented at the 2nd Asia Pacific Conference on Problem-Based Learning: Education Across Disciplines, December 4-7, 2000, Singapore. [5] Clark R. C. \& Mayer, R. E. . ELearning and the science of instruction: Proven guidelines for consumers and designers of multimedia learning (2nd ed.). San Francisco, CA: Pfeiffer \& Company. 2007.

[6] Jonassen, D. H., Peck, K. L., and Wilson, B. G. . Learning With Technology: A Constructivist Perspective, New Jersey: Merrill/Prentice Hall. 1999. 